\title{
Spatial and temporal patterns in summer ichthyoplankton assemblages on the eastern Bering Sea shelf 1996-2000
}

\author{
J. T. DUFFY-ANDERSON, ${ }^{1, *}$ M. S. BUSBY, ${ }^{1}$ \\ K. L. MIER, ${ }^{1}$ C. M. DELIYANIDES ${ }^{1}$ AND \\ P. J. STABENO ${ }^{2}$ \\ ${ }^{1}$ National Oceanic and Atmospheric Administration, National \\ Marine Fisheries Service, Alaska Fisheries Science Center, 7600 \\ Sand Point Way NE, Seattle, WA 98115-6349, USA \\ ${ }^{2}$ National Oceanic and Atmospheric Administration, Pacific \\ Marine Environmental Laboratory, 7600 Sand Point Way NE, \\ Seattle, WA 98115-6349, USA
}

\begin{abstract}
Larval and early juvenile fishes were sampled from the eastern Bering Sea (EBS) shelf during summer from 1996 to 2000. Data from these collections were used to examine spatial and temporal patterns in species assemblage structure and abundance. Cluster analyses based on Bray-Curtis dissimilarity coefficients were used to group species and stations according to similar abundance and species composition. Ordination techniques were used to verify groupings, and a nonparametric stepwise procedure using a Spearman correlation coefficient (BIO-ENV) was used to relate groupings to predominant environmental variables. These approaches revealed a pattern of station groupings that were generally related to bathymetry in 1996, 1997, 1999, and 2000, although no obvious relationship to geographic boundaries was observed in 1998 . Significant differences in species associations were observed in 1997 and 1998, and depressions in abundance were also noted among many species between 1997 and 1999. A regional, full primitive equation model was used to simulate float trajectories on the EBS shelf in each year to better relate fish distributional observations to prevailing current patterns. Model results indicated general variations in flow in several years, although 1998 stood out with stronger northeast flow than in any of the other years examined. Observed disruptions of larval and early juvenile fish assemblages could be related to the strong El-Niño
\end{abstract}

*Correspondence. e-mail: janet.duffy-anderson@noaa.gov Received 28 October 2003

Revised version accepted 27 January 2005 event of 1997-98 in the EBS. If this idea is confirmed, our study suggests that larval and juvenile fish are sensitive and respond relatively quickly $(1-2 \mathrm{yr})$ to environmental perturbations, and as such, may be timely indicators of environmental change.

Key words: assemblages, Bering Sea, El Niño, fish larvae, juveniles, spatial distribution

\section{INTRODUCTION}

Ichthyoplankton assemblages may be the result of 'adaptive convergence' (McGowen, 1993), whereby larvae of different species tend to co-occur as a result of parallels in their life histories. For example, similarities in the reproductive patterns of adults (Gray and Miskiewicz, 2000), exposure to similar hydrographic processes such as currents or upwelling (Smith and Suthers, 1999), or convergence with a similar resource such as abundant zooplankton (Moser and Smith, 1993) can all lead to discrete groupings of co-occurring larval fish species. In addition, ichthyoplankton assemblages have been shown to be distinct within oceanographic regions (e.g. water masses) and respond to environmental change (Moser et al., 1987). However, these associations are not fixed in time or space; rather, they are flexible and by their nature, sensitive to external perturbations. The degree of distortion varies: small-scale disturbances in time and space such as variations in local turbulence, upwelling, or instabilities in currents have short-lived impacts on assemblages, briefly disrupting them, but allowing their constituents to re-form relatively quickly after the perturbation has passed. Large-scale stresses such as climate variation (e.g. Pacific Decadal Oscillation, Arctic Oscillation, or climate change) potentially have the ability to break associations completely (Anderson and Piatt, 1999), prompting a distinct, long-term reorganization of community dynamics. We were interested in determining the degree of impact a meso-scale event, specifically the 1997-98 El Niño, had on associations of larval and early-stage juvenile fishes in the eastern Bering Sea (EBS). Other studies have examined the effects of El Niño on distribution and abundance of temperate larval fishes along the US 
west coast (Brodeur et al., 1985; Moser et al., 1987; Doyle, 1995), although effects in the EBS are undocumented.

The impact of El Niño-Southern Oscillation (ENSO) events at higher latitudes in the eastern North Pacific (Niño North) (Wooster and Fluharty, 1985), particularly the western Gulf of Alaska (GOA) and the EBS, is primarily related to atmospheric couplings and the strength and position of the Aleutian Low (Hollowed et al., 2001). While not all El Niño events manifest Niño North effects, the El Niño event of 1997-98 was particularly intense (Chavez et al., 1999, 2002) and unusual conditions occurred in the EBS in 1997. For example, a large coccolithophore bloom (Emiliania huxleyi) was visible from SeaWiFS images. While smaller blooms have been observed, this was a report of a bloom which covered much of the Bering Sea shelf (Sukhanova and Flint, 1998; Vance et al., 1998). In addition, in 1997 the ocean was characterized by a shallow mixed layer $(<15 \mathrm{~m})$ and record-high sea-surface temperatures $\left(>14^{\circ} \mathrm{C}\right)$ (Overland et al., 2001). There was also decreased transport of slope water onto the EBS shelf (Stabeno et al., 2001). Finally, the unusually shallow mixed layer resulted in a phytoplankton bloom below the surface mixed layer, and the depletion of nutrients and chlorophyll was observed (Stockwell et al., 2001), although no effects on zooplankton biomass were noted (Napp et al., 2002).

The effects of Niño North events on adult distribution and recruitment of North Pacific fishes have been documented. Kruse (1998) suggested that anomalous conditions in the EBS associated with the 1997-98 El Niño played an important role in the low salmon (Oncorhynchus spp.) returns during 1997 and 1998 in western Alaska. Bailey et al. (1995) showed that there were few effects of ENSO events (1957-58, 1982-83, 1991-93) on the distribution of GOA groundfishes, although recruitment of Pacific halibut (Hippoglossus stenolepis) and arrowtooth flounder (Atheresthes stomias) in the GOA may be enhanced by changes in circulation associated with ENSO events (Bailey et al., 1995; Bailey and Picquelle, 2002). Finally, Hollowed et al. (2001) suggested that increases in recruitment of gadid stocks in the GOA may be associated with Niño North conditions.

Objectives of this study were to: (1) describe midwater assemblages of larval and juvenile fishes on the EBS shelf in summer, (2) examine the interannual stability of assemblages, with particular interest in potential assemblage variations that could be associated with the 1997-98 El Niño, and (3) relate observations to oceanographic conditions.

\section{MATERIALS AND METHODS}

Field collections

Samples used in this study were collected from the EBS shelf during a series of cooperative research cruises between scientists at the Alaska Fisheries Science Center (AFSC) and Hokkaido University, Japan, on the T/S Oshoro Maru from 1996 to 2000. In late July of each year (Table 1) a grid of stations on the EBS shelf was occupied, extending eastward and south from the Pribilof Islands (Fig. 1). Conductivity temperature depth (CTD) casts were made immediately prior to fish sampling at approximately half the total number of stations in any given year. Larval and juvenile fish were collected at each grid station using a modified beam trawl (MBT), fitted with a $3 \times 2$ $\mathrm{mm}$ oval mesh net and a $1-\mathrm{mm}$ mesh cod end. The MBT (mouth opening $5 \mathrm{~m}^{2}$ ) was designed to collect late larval and early juvenile stage fishes in the midwater, and is similar to a Methot trawl (Methot, 1986). The MBT differs from the Methot trawl by not having a depressor and by containing weight within the tubular frame. A flowmeter was fitted into the mouth of the MBT to determine volume filtered. All tows were oblique and were made from $200 \mathrm{~m}$ (or $10 \mathrm{~m}$ off bottom if shallow) to the surface. Net depth was measured using an acoustic netsonde. Upon retrieval, all samples were preserved in sodium borate-buffered $5 \%$ formalin. It should be noted here that oblique towing provides depth-integrated information, so larvae and juveniles collected were likely to be derived from more than one water mass. However as oblique collections took place in all years, the effects of combining larvae from multiple water masses is normalized across years.

Supplemental surface and bottom temperature data were obtained from AFSC annual bottom trawl surveys of the EBS shelf in summer (June-August). Only temperature data collected from within the same geographic extent as the present study were used (G. Walters, NOAA/National Marine Fisheries Service, personal communication).

Table 1. Cruise information for data used in this study.

\begin{tabular}{lll}
\hline Year & Dates & Number of stations \\
\hline 1996 & July 17-August 2 & 24 \\
1997 & July 18-August 2 & 26 \\
1998 & July 18-August 1 & 27 \\
1999 & July 20-August 1 & 20 \\
2000 & July 21-August 3 & 21 \\
\hline
\end{tabular}


Figure 1. Map of the eastern Bering Sea shelf and major currents (inset). Grid stations for surveys denoted by dots. Boxed area encloses 'core stations' (see text) used to examine interannual variations in fish abundance.

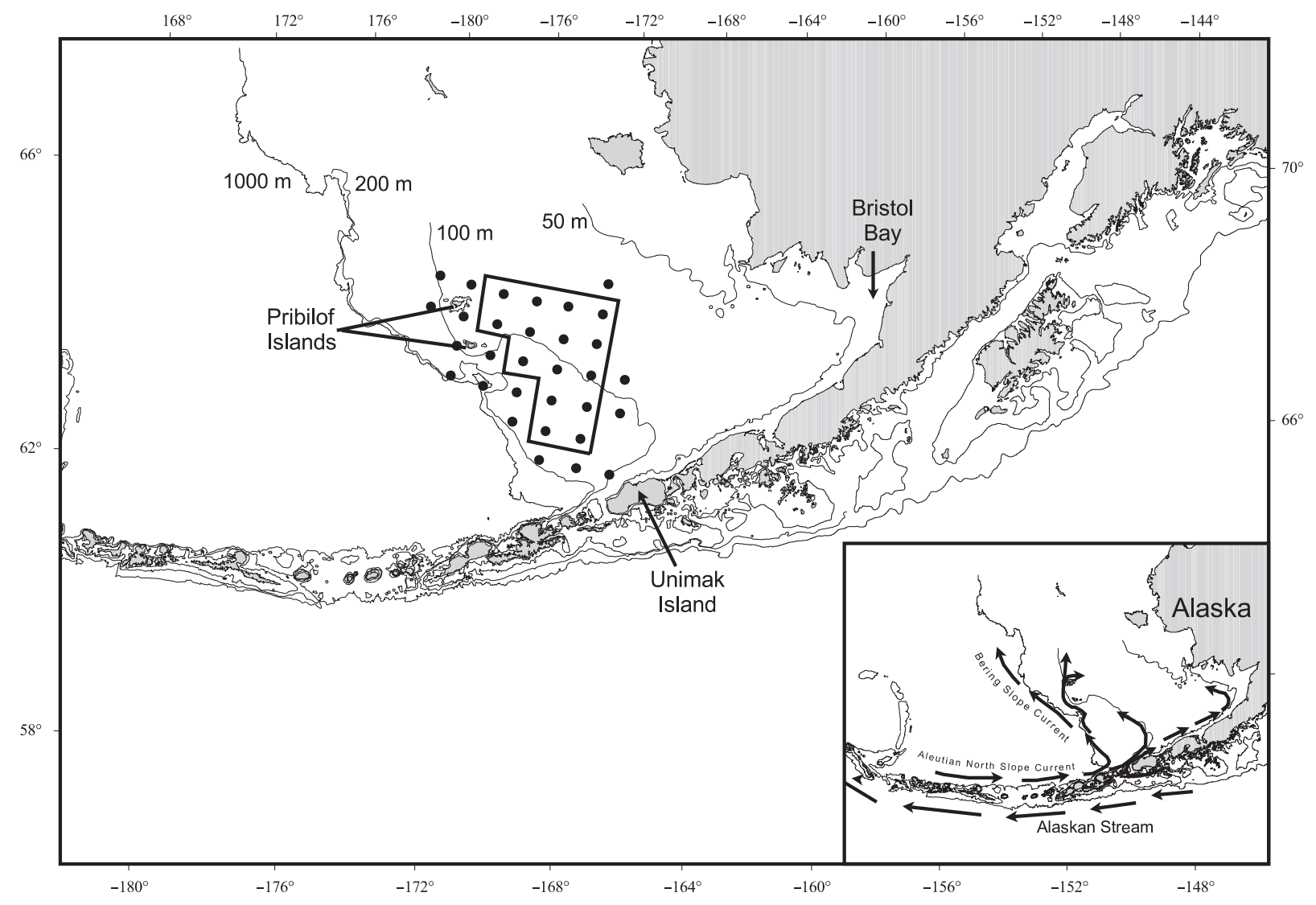

\section{Laboratory analyses}

Samples were sorted and fishes were identified to the lowest taxonomic level possible at the Plankton Sorting and Identification Center in Szczecin, Poland. Taxonomic identifications were verified at the AFSC in Seattle, WA. Some fish were categorized as species complexes (ex: Atheresthes spp., Sebastes spp.) due to limitations associated with identifying larval stages to the species level. All fishes were measured for standard length (SL) to the nearest $\mathrm{mm}$. The separation point between larvae and juveniles for Theragra chalcogramma and Gadus macrocephalus was $25.0 \mathrm{~mm} \mathrm{SL}$ based on the size at transformation of $T$. chalcogramma determined by Brown et al. (2001). Catch in each tow was converted to catch per $10 \mathrm{~m}^{2}$ of sea surface area.

\section{Statistical analyses}

Approaches used were similar to those described in Doyle et al. (2002), but a brief synopsis follows. Rare species were removed from the analyses using the criterion that a species needed to be present in at least $5 \%$ of the samples to be included. Removal of rare species was deemed appropriate because rare species were not likely to contribute significantly to the broader spatial and temporal patterns being investigated and they would tend to disrupt the clustering patterns that might exist without them. Separate hierarchical clustering analyses for species and stations (expressed as abundance in catch $10 \mathrm{~m}^{-2}$ ) were performed for each year using the Bray-Curtis similarity coefficient. This method was chosen as cluster analyses resolve inter-species associations, allowing an examination of community structure. The Flexible Beta clustering method was used with $\beta=-0.25$. To give less weight to the more abundant species which would otherwise dominate the dissimilarity coefficient, a fourth root transformation was used before calculating the Bray-Curtis coefficient for clustering stations (samples). However, when clustering species, the data were standardized by species totals, in place of a transformation, in order to preserve the relative abundance of each species (Clarke and Warwick, 2001). This allowed examination of similarity in species patterns over varying scales of abundance. 
Groupings of species and stations from the cluster dendrograms were identified by drawing lines across each dendrogram where the tree branching was the longest (indicating cluster stability). Occasionally subjective criteria were used to refine cluster groupings, including examining cluster groupings for internal consistency and identification of outlier groups. A reordered species-station matrix was created using a two-way joining analysis that plotted species and station dendrograms together to show the relative abundance of each species grouping at the various station groupings. Station groupings were plotted on a map of the sampling area to determine if geographic distinctions were apparent.

Non-metric multidimensional scaling (NMDS) was used to provide another graphical means of showing the species/station groupings identified from the cluster analyses. A blocked analysis of similarity (ANOSIM) was used to test for differences between years (see Clarke and Warwick, 2001), followed by a similarity percentages (SIMPER) analysis which helped to define the primary species that best explain each significant difference. In order to see if there were any relationships between physical data (collected from CTD casts) and the cluster groups or gradients along the ordination, several physical variables were measured at these same stations including surface temperature, bottom temperature, salinity, oxygen, and bottom depth. These were initially investigated using bubble plots of the physical variables, superimposed on the NMDS plots with cluster groups circled. This method reveals gradients with respect to species composition. Then a BIO-ENV analysis was performed (Clarke and Warwick, 2001) to determine which physical variables were most related to the species composition.

Variations in species abundance and species length were evaluated between years. As there were slight variations in the geographic area sampled in each year, variations in species abundance were examined at a subset of stations of the study, which included only those. Fifteen stations were identified as having been sampled in all study years, and variations in abundance and length among the years were evaluated from this 'core' group of stations (Fig. 1). These analyses were conducted for each of the seven most commonly collected taxa within this core group of stations, T. chalcogramma, G. macrocephalus, Sebastes spp., Hippoglossoides elassodon, Zaprora silenus, Lepidopsetta polyxystra, and Atheresthes spp., as these were the only taxa available in sufficient numbers across all years. Nested ANOVAs (weighted by the haul CPUE for length analyses) were used to test for length differences among years, and blocked ANOVAs were used to test for differences in abundance. These were followed by multiple comparison of means tests to see which years were significantly different.

\section{Drifter trajectories model}

Currents over the EBS shelf are relatively weak and vary significantly from year to year. We used trajectories from a regional, full primitive equation model (Hermann et al., 2002), the Northeast Pacific Regional Ocean Model System (NEPROMS) to simulate float trajectories on the EBS shelf in each year (1996-2000). This model has been used as part of NE GLOBEC and has been very successful in replicating the general patterns of flow in the Gulf of Alaska. While there has been no careful evaluation of how well the model works in the Bering Sea, the general patterns of flow and water column structure appear to be realistic. Simulated drifters were released on April 1 of each modeled year, immediately north of Unimak Island in a $7 \times 7$ grid. Fifteen drifters were released at each grid point at varying depths (from the surface to approximately $40 \mathrm{~m}$ ) and tracked for 90 days. The Unimak Island area was chosen as the drifter release site as it is a known spawning area for a variety of species in the Bering Sea, and it is likely that a significant portion of the larval and juvenile fishes collected in this study in July were originally spawned in the Unimak vicinity in early spring (Matarese et al., 2003).

\section{RESULTS}

\section{Species composition}

A total of 48,043 fishes representing 42 different species from 17 different families were collected over the 5 -yr sampling period. Species diversity was lowest in 2000, with only 17 species collected compared with 22-28 species in the other years (Table 2). Gadids dominated the catch, and T. chalcogramma was by far the most abundant species collected in all years, comprising $93.9 \%$ of the total number of fish caught. Gadids collected were larvae and age- 0 juveniles ( $T$. chalcogramma size range $=8.4-67.0 \mathrm{~mm} \mathrm{SL}$, mean size $=27.2 \mathrm{~mm} \mathrm{SL}$, G. macrocephalus size range 18.2 $64.0 \mathrm{~mm} \mathrm{SL}$, mean size $=35.5 \mathrm{~mm} \mathrm{SL}$ ), while larvae comprised the majority of the catch for other species collected. It should be noted that larval stages were probably not assessed completely with the MBT due to the large mesh size.

\section{Spatial patterns}

Cluster analyses revealed a pattern of species and station groupings that were generally related to 
Table 2. Fish taxa present in at least $5 \%$ of the samples. ' $\mathrm{X}$ ' indicates whether that species was collected in that year. The total number of species collected in each year is given at the bottom (total includes rare species that were removed before analyses).

\begin{tabular}{|c|c|c|c|c|c|c|}
\hline Species name & Common name & 1996 & 1997 & 1998 & 1999 & 2000 \\
\hline Leuroglossus schmidti & Northern smoothtongue & & $X$ & $\mathrm{X}$ & $\mathrm{X}$ & $\mathrm{X}$ \\
\hline Gadus macrocephalus & Pacific cod & $X$ & $\mathrm{X}$ & $\mathrm{X}$ & $X$ & $\mathrm{X}$ \\
\hline Theragra chalcogramma & Walleye pollock & $X$ & $\mathrm{X}$ & $\mathrm{X}$ & $\mathrm{X}$ & $\mathrm{X}$ \\
\hline Sebastes spp. & Unidentified rockfishes & $X$ & $\mathrm{X}$ & $X$ & $X$ & $\mathrm{X}$ \\
\hline Dasycottus setiger & Spinyhead sculpin & $\mathrm{X}$ & $\mathrm{X}$ & $\mathrm{X}$ & & $\mathrm{X}$ \\
\hline Icelus spp. & Unidentified sculpins & $X$ & $\mathrm{X}$ & $\mathrm{X}$ & $X$ & \\
\hline Hemilepidotus spp. & Irish lords & $\mathrm{X}$ & $\mathrm{X}$ & & $\mathrm{X}$ & \\
\hline Psychrolutes spp. & Unidentified fathead sculpins & $\mathrm{X}$ & $\mathrm{X}$ & $\mathrm{X}$ & & \\
\hline Bathyagonus alascanus & Gray starsnout & $X$ & $X$ & $\mathrm{X}$ & $\mathrm{X}$ & $\mathrm{X}$ \\
\hline Bathyagonus spp. & Unidentified poachers & $\mathrm{X}$ & & $\mathrm{X}$ & $\mathrm{X}$ & $\mathrm{X}$ \\
\hline Podothecus acipenserinus & Sturgeon poacher & $\mathrm{X}$ & $\mathrm{X}$ & $\mathrm{X}$ & $\mathrm{X}$ & \\
\hline Liparis spp. & Unidentified snailfishes & $\mathrm{X}$ & $\mathrm{X}$ & $\mathrm{X}$ & $\mathrm{X}$ & \\
\hline Lumpenus maculatus & Daubed shanny & $\mathrm{X}$ & $\mathrm{X}$ & $\mathrm{X}$ & $\mathrm{X}$ & \\
\hline Zaprora silenus & Prowfish & $\mathrm{X}$ & $\mathrm{X}$ & $\mathrm{X}$ & $X$ & \\
\hline Atheresthes spp. & Arrowtooth/Kamchatka flounder & $\mathrm{X}$ & $\mathrm{X}$ & $\mathrm{X}$ & $\mathrm{X}$ & $\mathrm{X}$ \\
\hline Hippoglossoides elassodon & Flathead sole & $\mathrm{X}$ & $\mathrm{X}$ & $\mathrm{X}$ & $\mathrm{X}$ & $\mathrm{X}$ \\
\hline Lepidopsetta bilineata & Southern rock sole & & & $\mathrm{X}$ & $X$ & $\mathrm{X}$ \\
\hline Lepidopsetta polyxystra & Northern rock sole & $X$ & $\mathrm{X}$ & $X$ & $X$ & $\mathrm{X}$ \\
\hline Reinhardtius hippoglossoides & Greenland halibut & $X$ & $\mathrm{X}$ & $X$ & $X$ & $\mathrm{X}$ \\
\hline Total & & 28 & 22 & 22 & 28 & 17 \\
\hline
\end{tabular}

bathymetry. In 1996, four distinct species groups and three station groups were identified (Fig. 2). Group A species was composed of Atheresthes spp., Lumpenus maculatus, Icelus spp., R. hippoglossoides, and Sebastes spp., which were collected in highest numbers at Station Subgroup 2A, near the Pribilof Islands, but in lower numbers at Station Group 3, located on the outer shelf between the 100- and 200-m isobaths. Group B species was composed of Bathyagonus alascanus, Z. silenus, and G. macrocephalus, which tended to co-occur at Station Group 3, although a number of G. macrocephalus were also collected at Station Group 1 , in the northeast corner of the grid, inshore of the 100-m isobath. Group C species was composed of H. elassodon, T. chalcogramma, and L. polyxystra, which were usually collected in highest numbers at Station Group 2, although it should be noted that $T$. chalcogramma were ubiquitous and were collected in varying abundances at all stations, and $H$. elassodon were also abundant at Station Group 3. Finally, Group D species was composed of just two taxa, a liparid species complex (Liparis spp.) and Podothecus acipenserinus. These usually co-occurred at Station Group 2, with somewhat higher numbers of individuals collected at Subgroup 2A, located nearer to the Pribilof Islands, than at Subgroup 2B, farther from the Pribilof Islands and inshore of the $100-\mathrm{m}$ isobath.
This general pattern of station clustering relative to bathymetry was similar in 1997, 1999, and to a somewhat lesser degree, 2000, with clusters occurring in the general vicinity of the Pribilof Islands, in the northeast corner of the grid inshore of the $100-\mathrm{m}$ isobath, and between the 100- and 200-m isobaths. However, station clustering appeared very different in 1998, with no obvious clusters associated with bathymetry and a number of 'outlier' groups (clusters 4, 5, and 6) identified (Figs 3 and 4). Outliers tended to be those stations at which large numbers of one species were collected, for example, station cluster 6 which was composed only of large numbers of $L$. maculatus but no other species, or stations which were composed of species that oddly co-occurred, such as station cluster 4, which was composed of $H$. elassodon, B. alascanus, and Sebastes spp.

Results from three-dimensional NMDS analyses of stations generally supported groups derived from clustering analysis of stations in that only 1998 stood out as being different from other years. Results from the ANOSIM however suggested that both 1997 and 1998 were different from each other and from all other years in terms of species composition $(P<0.001)$. The species contributing most to these differences, as shown by the SIMPER analysis, were T. chalcogramma, H. elassodon, L. polyxystra, G. macrocephalus, Sebastes 
Figure 2. Results of a two-way joining analysis of species/station clusters showing relative abundance of fishes collected in 1996. White lines indicate groupings, dotted line indicates subgroups. Individual species clusters identified by letters, station cluster identified by numbers. Results for 1996 are representative of results for 1997, 1999, and 2000.

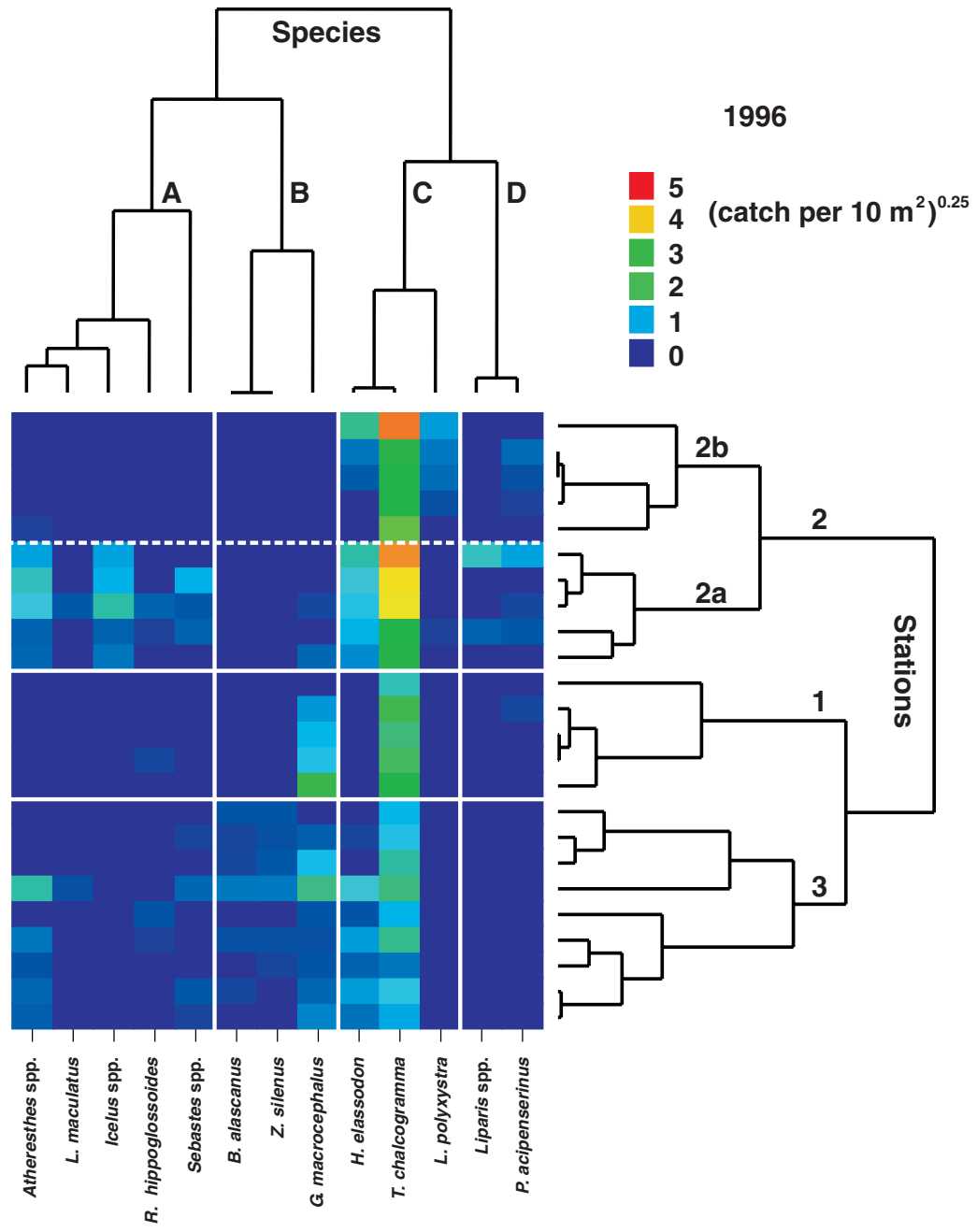

spp., Atheresthes spp., B. alascanus, and R. hippoglossoides.

Species groupings among the years were more variable (Table 3 ), with cluster constituents varying across years. Atheresthes spp. and Sebastes spp. clustered together in all years, suggesting that larvae/juveniles of these two taxonomic groupings have distinct life history parallels that consistently act to distribute them in similar habitats. Other species associations were not as consistent, although G. macrocephalus often co-occurred with $Z$. silenus and $H$. elassodon, and peak abundances of G. macrocephalus rarely co-occurred with peak abundances of $T$. chalcogramma (except in 2000). The NMDS analyses generally supported the cluster analyses of species.

\section{Abundance and size}

There were significant interannual variations in ichthyoplankton and juvenile fish abundance for selected species ( $T$. chalcogramma, H. elassodon, G. macro- cephalus, and L. polyxystra) within the core grid (Table 4), and considerable depressions in mean abundance in 1997-99 were noted for five of the seven species examined ( $T$. chalcogramma, $H$. elassodon, G. macrocephalus, Atheresthes spp., and Z. silenus) (Fig. 5). Significant differences in fish size were also detected among years for $H$. elassodon, L. polyxystra, T. chalcogramma, and Sebastes spp., although the lack of a consistent pattern across taxa precluded further analyses of size data.

\section{Environmental patterns}

The region of this study can be characterized by three distinct hydrographic regions. The middle shelf (ocean depth $50-100 \mathrm{~m}$ ) has a two-layer structure, with a tidally mixed bottom layer insulated by the surface layer, so it retains cold winter temperatures. The coldest bottom temperatures over the EBS occur here, since a combination of ice, winter cooling and strong storms mix the whole water column. The outer shelf 


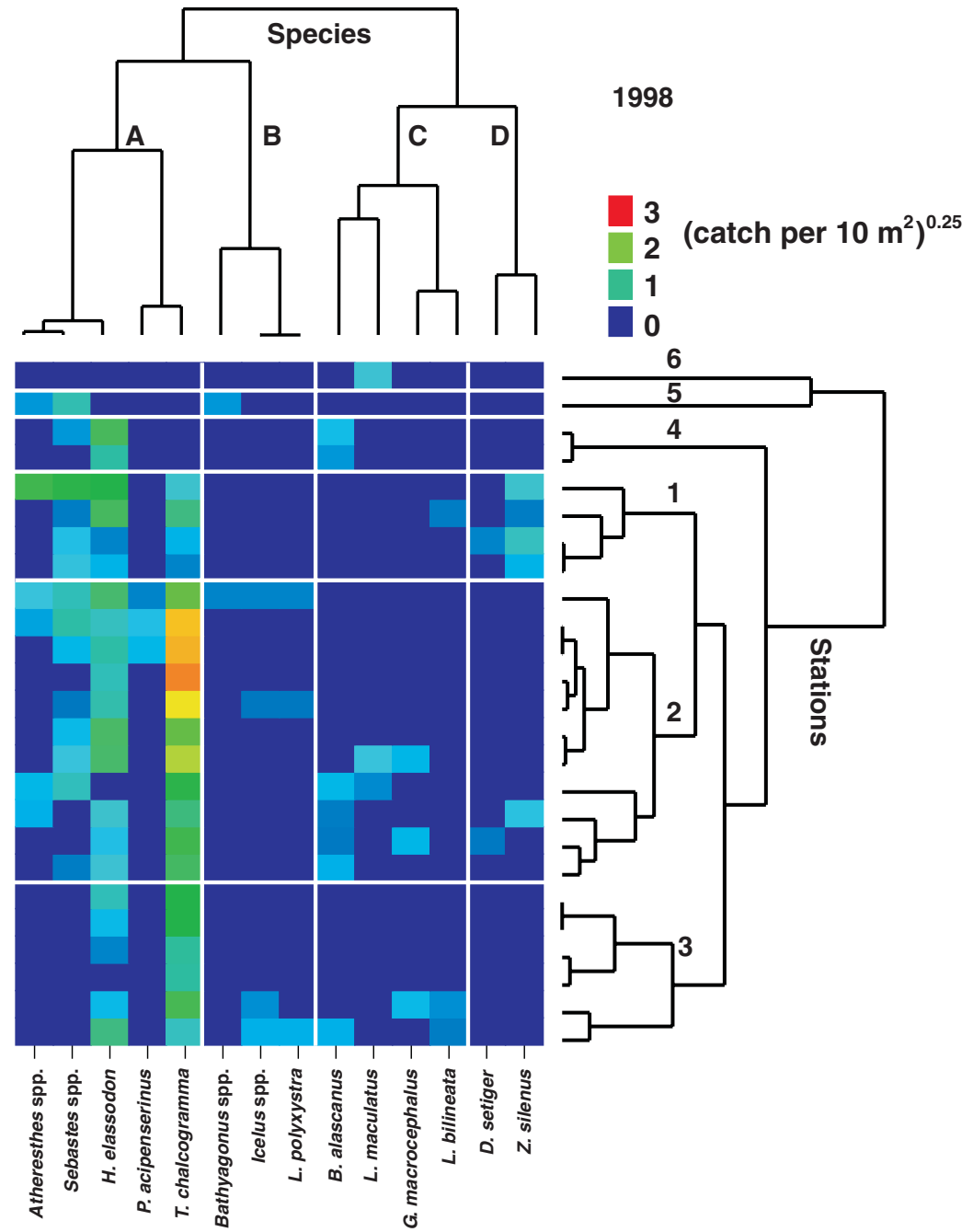

Figure 3. Results of a two-way joining analysis of species/station clusters showing relative abundance of fishes collected in 1998. White lines indicate groupings. Individual species clusters identified by letters, station cluster identified by numbers.
$(100-180 \mathrm{~m})$ is oceanic with surface and bottom mixed layers separated by a transition layer. The region around Pribilof Islands is strongly modified by onshelf fluxes in the Pribililof Canyon, and flow is clockwise around the islands.

Bottom temperatures varied as a function of depth. Warm bottom temperatures $\left(4-6^{\circ} \mathrm{C}\right)$ were noted around the Pribilof Islands, particularly in 1996, and colder bottom temperatures occurred over the middle shelf $\left(2-3^{\circ} \mathrm{C}\right)$. There was a broad distribution of warm bottom water in 1997 and 1998, although 1999 had a broad distribution of cold water. Sea-surface temperatures reflected patterns observed from bottom temperature data. Warm water $\left(7-10^{\circ} \mathrm{C}\right)$ was distributed more broadly in 1997 and 1998, extending from inshore of the 100-m isobath out to the slope. Cooler water covered the majority of the study area in 1999, and $4-6^{\circ} \mathrm{C}$ surface temperatures were recorded over the entire survey area.
The BIO-ENV procedure indicated that bottom depth was the parameter that was most consistently correlated with the similarities of the biotic data. Bottom depth was the best match for the years 1997, 1998 and $2000\left(r_{\mathrm{s}}=0.71,0.38,0.65\right.$, respectively), and although temperature was the best match in 1996 and salinity in 1997, bottom depth was still well-correlated in these years. Furthermore, three-dimensional NMDS plots with bottom depth indicated that station clusters were related to bathymetry for the years 1996, 1997, 1999, and 2000, but not for 1998. No other measured physical variable (salinity, oxygen, surface and bottom temperatures) was notably related to the cluster groups or to ordination. Finally, ANOSIM tests for differences in species composition between depths (below and above $100 \mathrm{~m}$ depth) showed significant differences for all years, although 1998 had a lower $r$-statistic than other years $(1998 r=0.16$, in other years $r$ ranged between 0.28 and 0.50$)$. 
Figure 4. Map showing geographic positions of station groupings (identified by numbers) revealed by cluster analyses. Note prevalence of outlier station groupings $(4,5,6)$ in 1998.
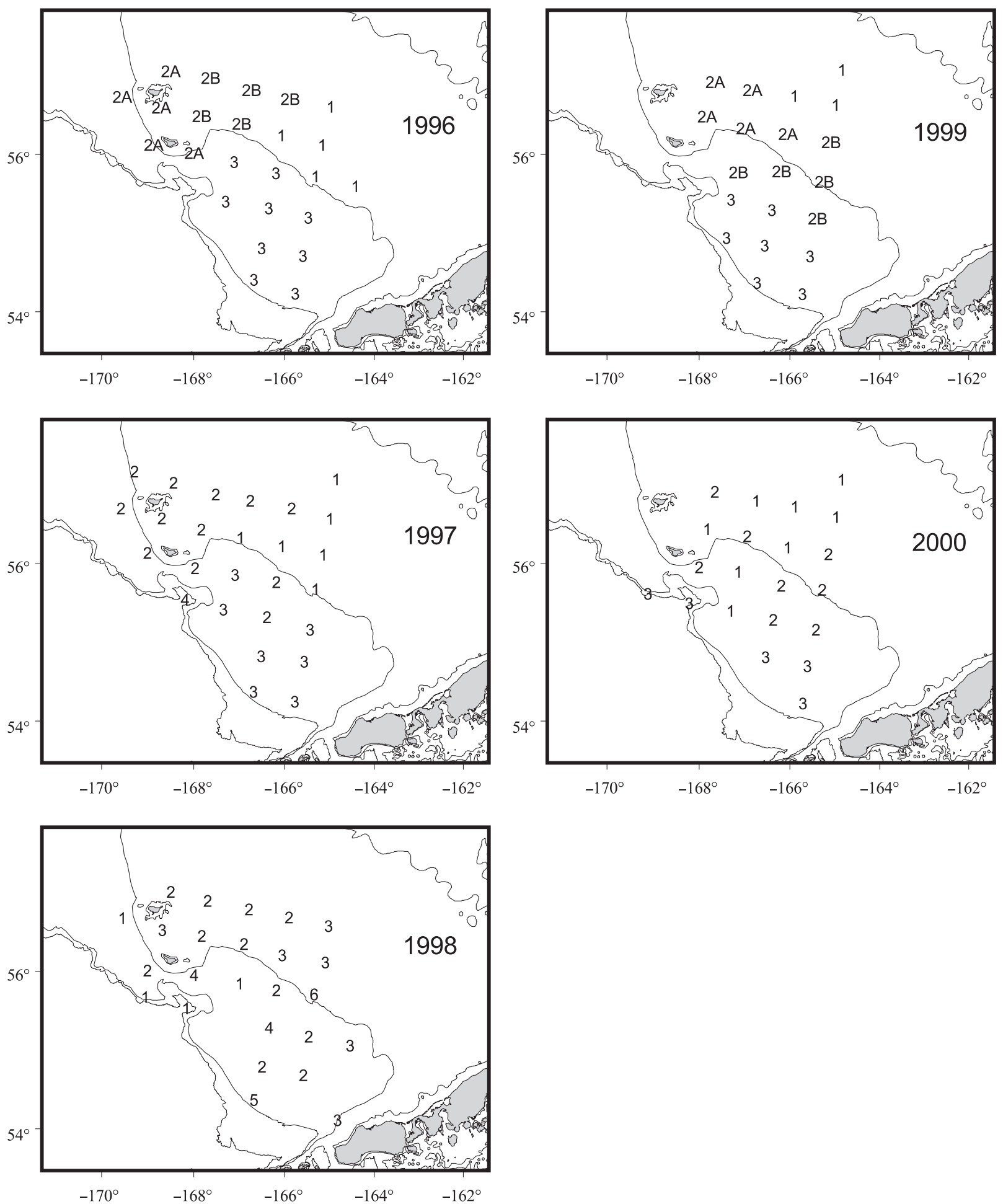

Drifter trajectories model

The general patterns of flow are evident in Figs 1 and 6. There is a weak flow along the $50-\mathrm{m}$ isobath that appears to be related to the strength of the inner front (Stabeno et al., 2002) and to the direction and strength of local wind forcing. There is strong 


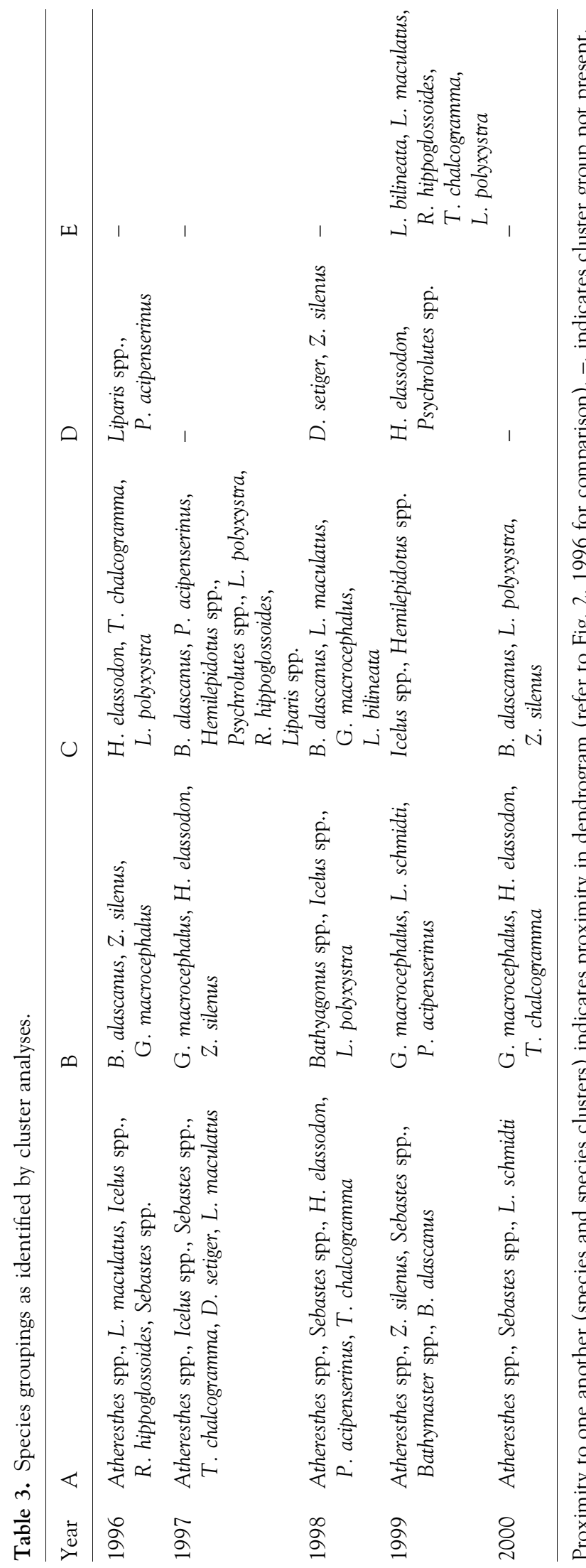

Table 4. Significant differences in interannual abundance of the seven most commonly collected species/taxa within the 'core' group of stations.

\begin{tabular}{llllll}
\hline Species & 1996 & 1997 & 1998 & 1999 & 2000 \\
\hline Atheresthes spp. & A & A & A & A & A \\
G. macrocephalus & B, C & A & A & A,B & C \\
Sebastes spp. & A & A & A & A & A \\
H. elassodon & A, B & A & B & A & A, B \\
L. polyxystra & A & B & A & A & A \\
T. chalcogramma & B & A, B & A & B & C \\
Z. silenus & A & A & A & A & A
\end{tabular}

Different letters indicate significant difference $(P \leq 0.05)$, like letters indicate no significant difference.

northward flow along the $100 \mathrm{~m}$ isobath, although flow varies greatly in position and strength from year to year. Results from the drifter trajectories model generally demonstrated flow along these two isobaths. However, simulations for 1997 and 2000 suggested a more disorganized pattern of flow, particularly to the north. In addition, trajectories of simulated drifters released in surface waters differed from those released at depth in 1998 and in 1999. In these two years, surface waters remained nearshore, while deeper water tended to flow along the $100-\mathrm{m}$ isobath. Most notably, in 1998 simulated drifters along the $50-\mathrm{m}$ isobath moved further to the northeast than those from any of other years examined, even penetrating into Bristol Bay during the short, 90-day simulation.

\section{DISCUSSION}

Larval and early juvenile fishes collected from our survey grid on the EBS shelf appear to form three distinct geographic multi-species assemblages: one located in the northwest portion of the survey grid, nearest to the Pribilof Islands ( $50-100 \mathrm{~m}$ depth) predominating on the middle EBS shelf, one located in the northeast corner of the survey grid, also on the middle shelf domain (50-100 m depth), and one between the 100 - and $200-\mathrm{m}$ isobaths on the outer EBS shelf. This pattern was fairly consistent among years, with the exception of 1998, which suggests that the distribution of larval and early juvenile fishes is primarily related to hydrography associated with bathymetric patterns and/ or specific geographic locales (e.g. the Pribilof Islands). Previous work in the North Pacific Ocean has also demonstrated that larval fish assemblages appear to be associated with either specific geographic locations or a bathymetric range. Doyle et al. (2002) identified a general shelf assemblage and a slope/deep water 
Figure 5. Interannual variations in abundance $( \pm 1 \mathrm{SE})$ of the seven most abundant taxa collected from the 'core' group of stations.
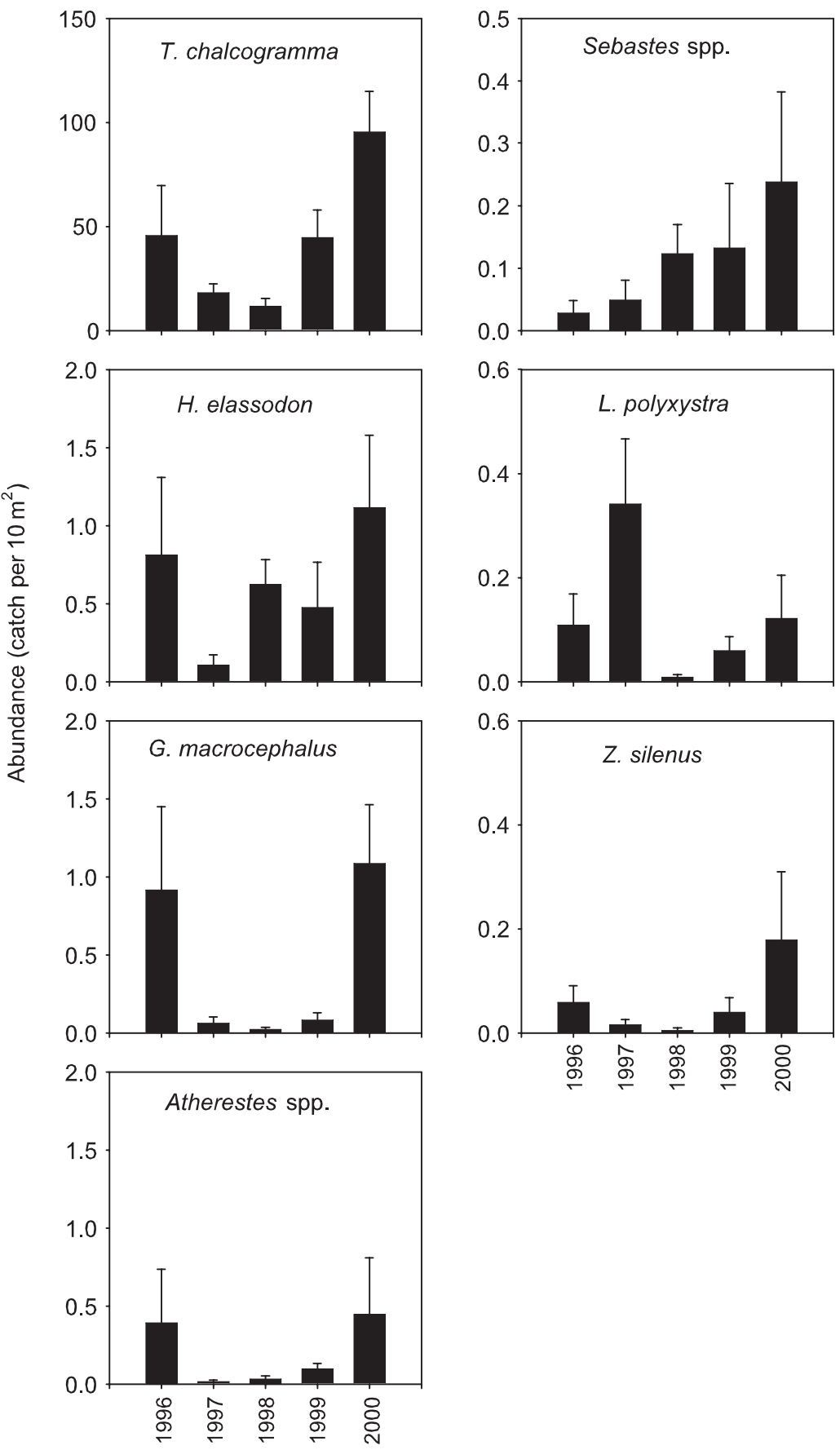
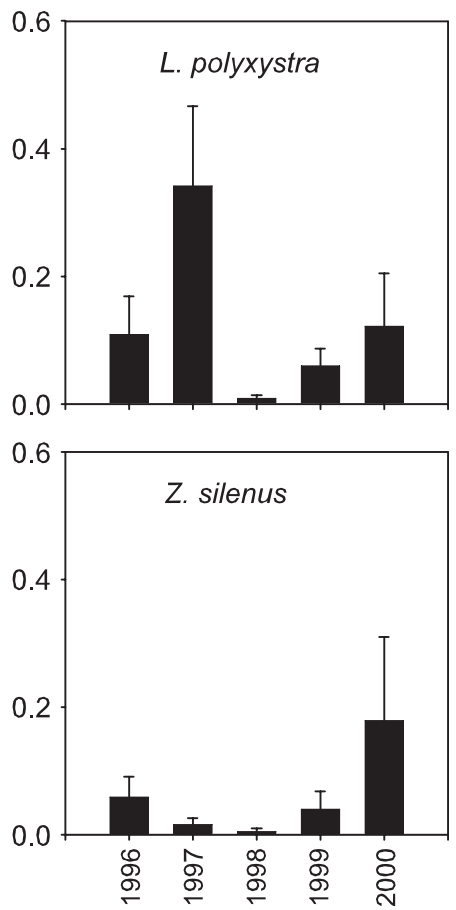

assemblage in both the south-eastern Bering Sea and in the Gulf of Alaska, and speculated that gradients in larval fish assemblage structure between the slope and the shelf may have been due to differences in spawning patterns of adults. The survey area in the present study only occasionally $(1997,1998,2000)$ included sampling over the slope; however we noted that larvae from fishes with presumed slope-spawning life-history strat- egies (Atheresthes spp., Sebastes spp., R. hippoglossoides, Z. silenus, L. schmidti) were often present in samples collected both from the slope and from the outer shelf. Larvae from slope-spawning fishes are likely transported up onto the EBS shelf via currents that connect the basin and the shelf (Stabeno et al., 1999a). Such onshelf flow is often evident in satellite-tracked (drogue depth $40 \mathrm{~m}$ ) trajectories. Onshelf flow is often 
Figure 6. Depth-discrete endpoints for 90-day simulated drifter trajectories from 1996 to 2000 . Symbols denote initial drifter release depths; red $=0-5 \mathrm{~m}$, blue $=5-20 \mathrm{~m}$, green $=20-45 \mathrm{~m}$.
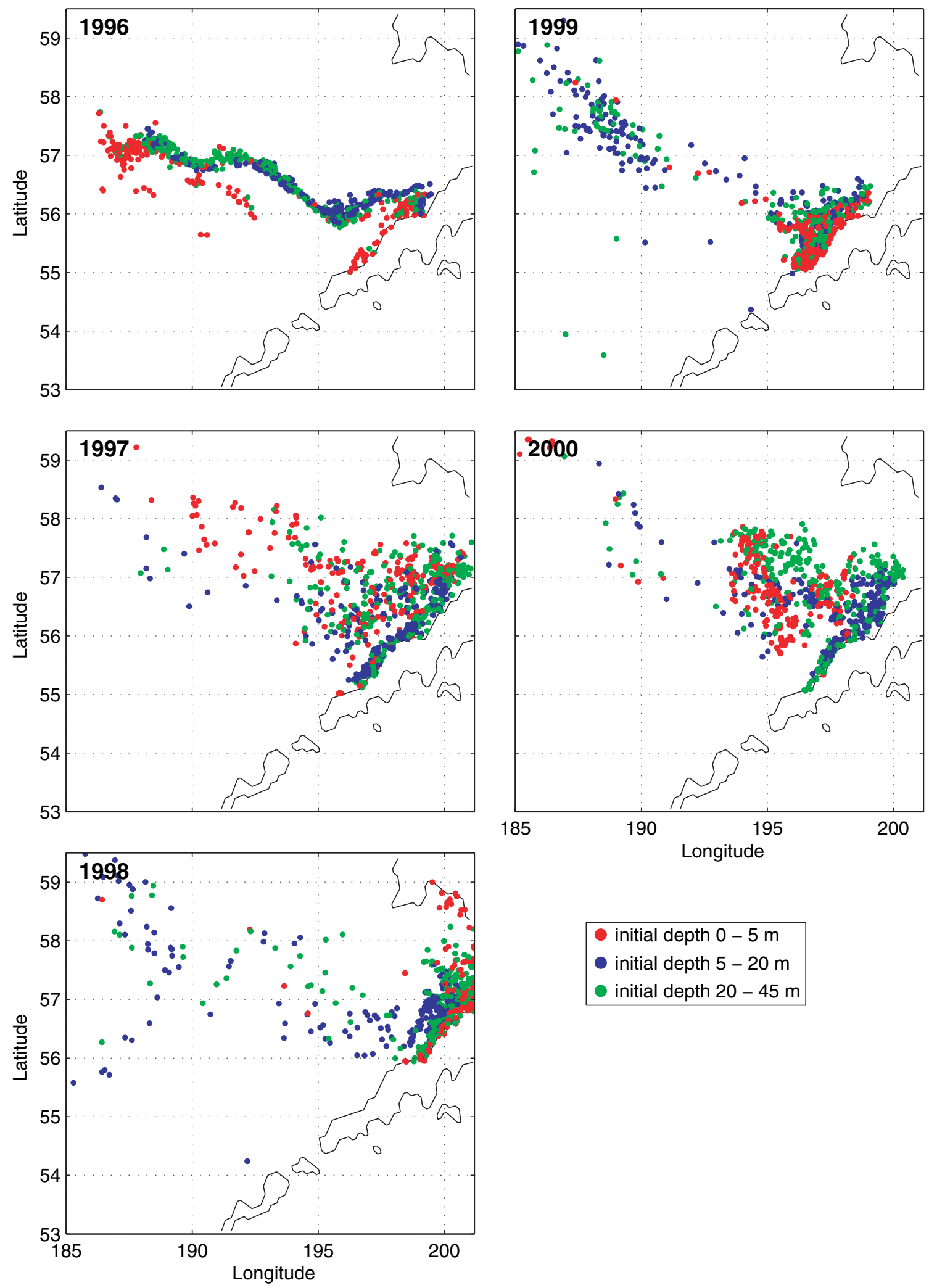

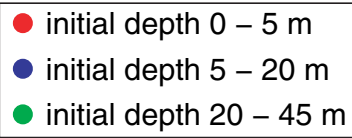

(C) 2005 Blackwell Publishing Ltd, Fish. Oceanogr., 15:1, 80-94. 
steered by topography, and both Bering Canyon and Pribilof Canyon support onshelf flux. The narrow shelf break south of St George Island accelerates shelf flow along the $100-\mathrm{m}$ isobath, and entrains water from the adjacent slope (Stabeno et al., 1999b). This water is then moved around the Pribilof Islands, moving heat, nutrients, and plankton onto the shelf. As such, larvae from fishes spawning on the slope south of the Pribilof Islands (note proximity of slope survey stations to the Pribilof Islands) are likely entrained in that current and transported up onto the shelf.

Species groupings were more dynamic than station groupings, and no single geographic area was consistently characterized by one assemblage of fishes in all years. Variations in larval species associations has been described elsewhere (Doyle et al., 2002), and our study provides additional evidence for the dynamic and flexible associations fish larvae and juveniles have with their environment. Interestingly, two taxa appeared to have a more consistent association with one another than did any of the other species groupings. Atheresthes spp. (in this study the complex is composed of A. stomias and A. evermanni) and Sebastes spp. (in this study the complex is most likely composed of S. alutus, S. borealis, and S. polyspinis, A. Kendall, National Marine Fisheries Service, personal communication) consistently grouped together in all years, suggesting that factors associated with their individual life histories act to bring the early life stages of these taxa together. It is known that arrowtooth flounder (A. stomias) has a slope-spawning life-history strategy (A. Matarese, unpublished data), although less is known about the reproductive strategy of Kamchatka flounder (A. evermanni). Likewise, the species most likely to comprise the Sebastes spp. complex also have slope-spawning strategies, suggesting that Atheresthes spp. larvae and Sebastes spp. larvae are entrained together in slope water that is ultimately transported up onto the shelf. However, it should be noted that other species with presumed slope-spawning strategies (for example, R. hippoglossoides, Hippoglossus stenolepis) did not always cluster with Atheresthes spp. and Sebastes spp., indicating that although Atheresthes spp. and Sebastes spp. appear to be closely linked, the mere fact that they are slope-spawned is probably not the sole reason for their association. Furthermore, several species collected in this study had wide geographic distributions, including Atheresthes spp. and Sebastes spp., and were collected across geographic strata.

We noted interannual variations in the geographic assemblages identified, as well as interannual variations in species clusters and abundance. Both NMDS and ANOSIM indicated that station clusters in 1998 differed from other years, although ANOSIM analyses suggested that species association in 1997 were also different. Interestingly, these two years coincide with the Niño North event of 1997-98, which suggests that factors associated with this event were sufficient to temporarily disrupt established patterns of geographic association. Of course, effects of Niño North conditions on the ecosystem are multiple, but several hypotheses are presented which could help to explain the observed differences in species and station groupings.

It has previously been shown that currents in the EBS are affected by El Niño-related forcing, and variations in current speed or directions could disrupt ichthyoplankton patterns of bathymetric association. Notably, model results for 1998 deviated from more typical observations, suggesting that flow in that year was strongly to the northeast, particularly the winddriven surface waters, with more limited movement of deep water $(20-45 \mathrm{~m})$ along the $100-\mathrm{m}$ isobath. The survey area associated with the present study straddled the $100-\mathrm{m}$ isobath, so it seems likely that at least some of the eggs and larvae spawned in the Unimak vicinity in March-May were collected on the T/S Oshoro Maru cruises as late larvae and early juveniles in July. Anomalous current flows around Unimak, such as were observed for 1998, could have served to transport larvae away from typical dispersal areas, resulting in the unusual species and bathymetric associations observed here.

Unfortunately, little is known about vertical distributions of fish eggs and early larvae on the Bering Sea shelf, so it is difficult to directly equate interannual differences in modeled depth-specific drifter trajectories with patterns of dispersal away from the Unimak Island vicinity. However, there is provisional information on vertical distribution for selected species. Theragra chalcogramma eggs appear to be most abundant in surface and near-surface waters $(<10 \mathrm{~m})$ in the EBS (Kendall, 2001), so it seems likely that anomalies in surface flow (such as in 1998) would affect their transport and, ultimately, the distribution of walleye pollock larvae and juveniles. Feeding stage H. elassodon larvae in the Gulf of Alaska are abundant in the upper water column (S.M. Porter, unpublished data), and may have a similar vertical distribution in the EBS. If so, it is likely that their larvae were also affected by variations in near-surface water transport in 1998. Finally, preliminary evidence suggests that at least some $L$. polyxystra larvae occur in surface waters (J.T. Duffy-Anderson, unpublished data), suggesting that they too may have been anomalously advected further to the northeast in 1998. 
In addition to variations in current patterns, the degree of water column mixing also likely influenced the dispersal of ichthyoplankton during the study period. The year 1998 has been characterized as a year of particularly intense and late wind and storm activity, and as a result the water column in that year, even in July, was much more thoroughly mixed relative to others. Indeed, time-series temperature profile data collected from biophysical mooring $2(56.87 \mathrm{~N}$, $164.05 \mathrm{~W})$ on the middle shelf domain for 1995-2000 demonstrate that subsurface (> 20-m depth) warming is only noted in 1998 (Hunt et al., 2002), and Stabeno et al. (2002) describe 1998 as a year with a significantly higher water column heat content relative to 1997. This high degree of water column heat and mixing may have also contributed to disruptions to bathymetric relationships in that year relative to other years.

Further, the distribution of spawning adults may affect distributions of larvae, and it is known that temperature variations influence the distribution of adult fishes on the EBS shelf. Kihara and Shimada (1988) noted that warm bottom temperatures prompted a wider distribution of Greenland turbot, $R$. hippoglossoides, yellow Irish lord, Hemilepidotus jordani, and thorny sculpin, Icelus spiniger, although cooler temperatures prompted a wider distribution of Pacific cod and arrowtooth flounder. Nichol (1998) suggested that distribution and migration patterns of yellowfin sole (Pleuronectes asper) in the EBS are related to temperature regime, and Wyllie-Echeverria and Wooster (1998) found that walleye pollock (T. chalcogramma) distribution on the EBS shelf varied significantly with the duration and southward extent of sea ice coverage. During our study, sea-surface temperatures on the EBS shelf in 1997 and 1998 were high, although in 1997, temperature anomalies greater than $+1^{\circ} \mathrm{C}$ were not detected in the EBS until June (Overland et al., 2001). Accordingly, it seems likely that the distribution of the adult spring spawning biomass of 1997 was probably little affected by El Niño-related shifts in temperature. However, Niño North conditions in the EBS persisted through the winter of 1997-98 and through the following spring and summer, so the distribution of spawning adults in 1998 and their resultant larvae were likely influenced.

Certainly other factors can affect the structure and distribution of ichthyoplankton assemblages as well. Other hydrographic phenomena such as small-scale and meso-scale currents (Gray and Miskiewicz, 2000; Hare et al., 2001), upwelling (Smith et al., 1999), and eddies (Cowen et al., 1993) can act to entrain or dis- rupt assemblages. In addition, studies have shown that habitat type (Harris and Cyrus, 2000), adult reproductive strategy (Somarakis et al., 2002), and a variety of other abiotic (salinity, pressure) and biotic variables (chlorophyll a, zooplankton) (Grioche et al., 1999) also influence fish assemblages. These and other variables may have also influenced distribution and abundance of fish larvae and juveniles in the EBS. In particular, densities of zooplankton on the EBS shelf are highly variable. For example, Baier and Napp (2003) have shown that concentrations of Calanus marshallae on the middle EBS shelf (1995-99) exhibit order-of-magnitude interannual variations in abundance, and Sugisaki et al. (1998) demonstrated substantial spatial heterogeneity in zooplankton abundance and diversity across the middle and outer EBS shelf. However, Napp et al. (2002) did not find any appreciable affect of the 1997-98 Niño North event on zooplankton biomass on the EBS shelf. Depressions in larval and juvenile fish abundances were noted for several taxa from 1997 to 1999, indicating that potential influences of Niño North conditions on fish abundance may be manifested rapidly. This study, however, cannot resolve whether observed differences in abundance were due to variations in survival or to other undetected alterations in fish distribution. Indeed, the modeled drifter data suggest interannual variations in flow which could have transported larvae outside the study region. On the other hand, abundance estimates of age-1 T. chalcogramma (Fig. 7) collected during summer (June-August) bottom trawl surveys made in the same geographic area from 1997 to 2001 (G. Walters,

Figure 7. Estimated population abundance of age-1 pollock (T. chalcogramma) on the eastern Bering Sea shelf (19972001) within the vicinity of the geographic area sampled during the present study (data courtesy of G. Walters, National Marine Fisheries Service, personal communication).

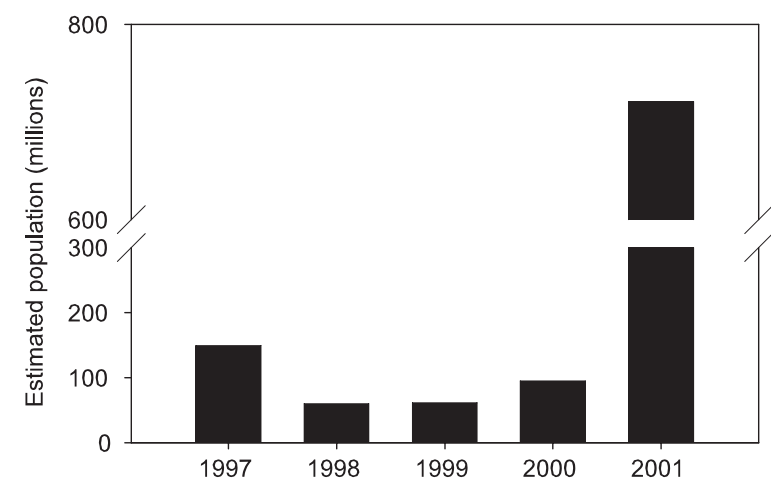


National Marine Fisheries Service, personal communication) suggest that low abundances observed among age- 0 individuals of this species (1996-2000, this paper) may have been due to variations in survival rather than variations in geographic distribution.

Our data suggest that summer larval and juvenile fish assemblages on the EBS shelf are fairly loose associations of species that are primarily related to bathymetric and/or geographic features (e.g. proximity to the Pribilof Islands). Our study also offers evidence that these assemblages can be distorted by external perturbations which may organize their constituents into new groupings. Disruptions appear to be interannually transient, and a return to previous conditions is possible. As ecological perturbations are more likely to be felt at lower trophic levels (e.g. zooplankton, ichthyoplankton) before effects are reflected at the top of the food chain, and given concerns over the effects of local-, meso-, and macro-scale perturbations on the structuring of the Bering Sea ecosystem, our study shows that larval and juvenile fish data are useful and timely indicators of environmental stress.

\section{ACKNOWLEDGEMENTS}

The authors would like to thank the officers, crew, and cadets of the T/S Oshoro Maru. Gary Walters generously provided data for age-1 walleye pollock abundance (1997-2001), and surface and bottom temperature data (1996-2000) collected from annual NOAA/AFSC summer bottom trawl surveys conducted on the EBS shelf. Dylan Righi provided modeled drifter information. Thanks to Drs Sei-ichi Saitoh and Yasunori Sakurai, Hokkaido University, for the opportunity to collaborate, and to Drs Ric Brodeur and Jeffrey Napp for discussion. Miriam Doyle, Ric Brodeur, Jennifer Lanksbury, Jeffrey Napp, Ian Perry, and an anonymous reviewer provided comments on an earlier version of this manuscript. This research was sponsored by the NOAA's Coastal Ocean Program through Southeast Bering Sea Carrying Capacity and is Eco-FOCI contribution S479.

\section{REFERENCES}

Anderson, P.J. and Piatt, J.F. (1999) Community reorganization in the Gulf of Alaska following ocean climate regime shift. Mar. Ecol. Prog. Ser. 189:117-123.

Baier, C.T. and Napp, J.M. (2003) Climate-induced variability in Calanus marshallae populations. J. Plank. Res. 25:771-782.

Bailey, K.M. and Picquelle, S.J. (2002) Larval distribution of offshore spawning flatfish in the Gulf of Alaska: potential transport pathways and enhanced onshore transport during ENSO events. Mar. Ecol. Prog. Ser. 236:205-217.
Bailey, K.M., Macklin, S.A., Shima, M. et al. (1995) ENSO events in the northern Gulf of Alaska, and its effects on selected marine fisheries. Calif. Coop. Oceanic Fish. Invest. Rep. 36:78-96.

Brodeur, R.D., Gadomski, D.M., Pearcy, W.G., Batchelder, H.P. and Miller, C.B. (1985) Abundance and distribution of ichthyoplankton in the upwelling zone off Oregon during anomalous El Niño conditions. Estuarine Coastal Shelf Sci. 21:365-378.

Brown, A.L., Busby, M.S. and Mier, K.L. (2001) Transformation from the larval to juvenile stage in walleye pollock (Theragra chalcogramma): the relationship between otolith and osteological development. Mar. Biol. 139:845-851.

Chavez, F.P., Strutton, P.G., Feely, R.A., Feldman, G.C., Foley, D.G. and McPhaden, M.J. (1999) Biological and chemical response of the equatorial Pacific Ocean to the 1997-98 El Niño. Science 286:2126-2131.

Chavez, F.P., Collins, C.A., Huyer, A. and Mackas, D.L. (2002) Observations of the 1997-1998 El Niño along the west coast of North America. Prog. Oceanogr. 54:1-5.

Clarke, K.R. and Warwick, R.M. (2001) Change in Marine Communities: an Approach to Statistical Analysis and Interpretation, 2nd edn. Plymouth: PRIMER-E.

Cowen, R.K., Hare, J.A. and Fahay, M.P. (1993) Beyond hydrography - can physical processes explain larval fish assemblages within the Middle Atlantic Bight? Bull. Mar. Sci. 53:567-587.

Doyle, M.J. (1995) The El Niño of 1983 as reflected in the ichthyoplankton off Washington, Oregon, and northern California. In: Climate Change and Northern Fish Populations. R.J. Beamish (ed.), Can. Spec. Publ. Fish. Aquat. Sci. 121:161-180.

Doyle, M.J., Mier, K.L., Busby, M.S. and Brodeur, R.D. (2002) Regional variation in springtime ichthyoplankton assemblages in the northeast Pacific Ocean. Prog. Oceanogr. 53:247-281.

Gray, C.A. and Miskiewicz, A.G. (2000) Larval fish assemblages in south-east Australia waters: seasonal and spatial structure. Estuarine Coast. Shelf Sci. 50:549-570.

Grioche, A., Kuobbi, P. and Harlay, X. (1999) Spatial patterns of ichthyoplankton assemblages along the eastern English Channel French coast during spring 1995. Estuarine Coast. Shelf Sci. 49:141-152.

Hare, J.A., Fahay, M.P. and Cowen, R.K. (2001) Springtime ichthyoplankton of the slope region off the United States of America: larval assemblages, relation to hydrography and implications for larval transport. Fish. Oceanogr. 10: 164-192.

Harris, S.A. and Cyrus, D.P. (2000) Comparison of larval fish assemblages in three large estuarine systems, KwaZulu-Natal, South Africa. Mar. Biol. 137:527-541.

Hermann, A.J., Stabeno, P.J., Haidvogel, D.B. and Musgrave, D. (2002) A regional tidal/subtidal circulation model of the southeastern Bering Sea: development, sensitivity analyses and hindcasting. Deep-Sea Res. (Part II: Topical Studies Oceanogr.) 49:5945-5967.

Hollowed, A.B., Hare, S.R. and Wooster, W.S. (2001) Pacific Basin climate variability and patterns of Northeast Pacific marine fish production. Prog. Oceanogr. 49:257-282.

Hunt, G.L. Jr, Stabeno, P., Walters, G. et al. (2002) Climate change and control of the southeastern Bering Sea pelagic ecosystem. Deep-Sea Res. II 49:5821-5853. 
Kendall, A.W. (2001) Specific gravity and vertical distribution of walleye pollock (Theragra chalcogramma) eggs. AFSC Processed Rep. 2001-01, 88 pp. Seattle, WA: Alaska Fisheries Science Center, National Marine Fisheries Service NOAA.

Kihara, K. and Shimada, A.M. (1988) Prey-predator interaction of walleye pollock Theragra chalcogramma and water temperature. Bull. Jpn Soc. Sci. Fish. 54:1131-1135.

Kruse, G.H. (1998) Salmon run failures in 1997-1998: a link to anomalous ocean conditions? Alaska Fish. Res. Bull. 5:55-63.

Matarese, A.C., Blood, D.M., Picquelle, S.J. and Benson, J.L. (2003) Atlas of abundance and distribution patterns of ichthyoplankton from the northeast Pacific Ocean and Bering Sea ecosystems based on research conducted by the Alaska Fisheries Science Center (1972-1996). NOAA Professional Paper 1:281 pp.

McGowen, G.E. (1993) Coastal ichthyoplankton assemblages, with emphasis on the southern California Bight. Bull. Mar. Sci. 53:692-722.

Methot, R.D. (1986) Frame trawl for sampling juvenile fish. Calif. Coop. Oceanic Fish. Invest. Rep. 27:267-278.

Moser, H.G. and Smith, P.E. (1993) Larval fish assemblages of the California Current region and their horizontal and vertical distributions across a front. Bull. Mar. Sci. 53:645-691.

Moser, H.G., Smith, P.E. and Eber, L.E. (1987) Larval fish assemblages in the California Current region, 1954-1960, a period of dynamic environmental change. Calif. Coop. Oceanic Fish. Invest. Rep. 28:97-127.

Napp, J.M., Baier, C.T., Brodeur, R.D., Coyle, K.O., Shiga, N. and Mier, K. (2002) Interannual and decadal variability in zooplankton communities of the southeast Bering Sea shelf. Deep-Sea. Res. II 49:5991-6008.

Nichol, D.G. (1998) Annual and between-sex variability of yellowfin sole, Pleuronectes asper, spring-summer distributions in the Bering Sea. Fish. Bull. US 96:547-561.

Overland, J.E., Bond, N.A. and Adams, J.M. (2001) North Pacific atmospheric and SST anomalies in 1997: links to ENSO? Fish. Oceanogr. 10:69-80.

Smith, K.A. and Suthers, I.M. (1999) Displacement of diverse ichthyoplankton assemblages by a coastal upwelling event on the Sydney shelf. Mar. Ecol. Prog. Ser. 176:49-62.
Smith, K.A., Gibbs, M.T., Middleton, J.H. and Suthers, I.M. (1999) Short term variability in larval fish assemblages of the Sydney shelf: tracers of hydrographic variability. Mar. Ecol. Prog. Ser. 178:1-15.

Somarakis, S., Drakopoulos, P. and Filippou, V. (2002) Distribution and abundance of larval fish in the northern Aegean Sea-eastern Mediterranean - in relation to summer oceanographic conditions. J. Plank. Res. 24:339-358.

Stabeno, P.J., Schumacher, J.D. and Ohtani, K. (1999a) The physical oceanography of the Bering Sea. In: Dynamics of the Bering Sea. T.R. Loughlin \& K. Ohtani (eds) Fairbanks, AK: University of Alaska Sea Grant, Program Rep. 96-01, pp. 1-28.

Stabeno, P.J., Schumacher, J.D., Salo, S.A., Hunt, G.L. and Flint, M. (1999b) Physical environment around the Pribilof Islands. In: Dynamics of the Bering Sea. T.R. Loughlin \& K. Ohtani (eds) Fairbanks, AK: University of Alaska Sea Grant, Program Rep. 96-01, pp. 193-215.

Stabeno, P.J., Bond, N.A., Kachel, N.B., Salo, S.A. and Schumacher, J.D. (2001) On the temporal variability of the physical environment over the south-eastern Bering Sea. Fish. Oceanogr. 10:81-98.

Stabeno, P.J., Reed, R.K. and Napp, J.M. (2002) Transport through Unimak Pass, Alaska. Deep-Sea Res. II 49:5919-5930.

Stockwell, D.A., Whitledge, T.E., Zeeman, S.I. et al. (2001) Anomalous conditions in the south-eastern Bering Sea, 1997: nutrients, phytoplankton, and zooplankton. Fish. Oceanogr. 10:99-116.

Sugisaki, H., Brodeur, R. and Napp, J. (1998) Summer distribution and abundance of macrozooplankton in the western Gulf of Alaska and southeastern Bering Sea. Mem. Fac. Fish. Hokkaido Univ. 5:96-112.

Sukhanova, I.N. and Flint, M.V. (1998) Anomalous blooming of coccolithophorids over the Eastern Bering Sea shelf. Oceanology 38:502-505.

Vance, T.C., Baier, C.T., Brodeur, R.D. et al. (1998) Aquamarine waters recorded for the first time in eastern Bering Sea. EOS Trans. Am. Geophys. Union 79:121, 126.

Wooster, W.S. and Fluharty, D.L. (1985) El Niño North. Seattle: Washington Sea Grant Program, 312 pp.

Wyllie-Echeverria, T. and Wooster, W.S. (1998) Year-to-year variations in Bering Sea ice cover and some consequences for fish distributions. Fish. Oceanogr. 7:159-170. 